\title{
Campeonato Mundial de Espada Feminina 2013: uma abordagem estatística sobre o match e o tempo cronometrado para a consecução de um toque
}

\author{
World Women's Epée Championship 2013: a statistical \\ approach about the match and time for achieving a hit
}

\author{
Tiago Magalhães França Silva', Marcos Daniel Motta Drummond
}

'Fundação Mineira de Educação e Cultura (FUMEC), Belo Horizonte, MG, Brasil.

Recebido em: junho 2015 / Aceito em: setembro 2015

franca_esgrima@yahoo.com.br

\section{RESUMO}

Objetivo: buscar dados para orientações quanto ao treinamento físico e tático da Espada, através de uma análise estatística de matches eliminatórios do Campeonato Mundial de Espada Feminina da FIE de 2013. Método: verificou-se a média, em cada match, do tempo cronometrado para a consecução de um toque. A população apresentada foram os 31 últimos matches da referida competição, analisando as 32 melhores colocadas. Resultados e considerações finais: constatou-se que a média geral é de 18,065s, com intervalo médio de 9,333 s entre o toque e a retomada do combate. No entanto, analisando os períodos, separadamente, verificou-se que o tempo para o toque é variável e diminui de acordo com a proximidade do fim do match.

Palavras-chave: Esgrima; Espada Feminina; Mundial Esgrima 2013; Match Espada.

\section{ABSTRACT}

Objective: look for meaningful data for guidance as to the physical and tactical Épée training. Method: statistical analysis of eliminatory matches of the World Women's Épée Championship of Federation Internationale D'escrime (FIE) 2013. We calculated the average time to achieve a hit in each match. Population was the last 31 matches of the refered competition, analyzing the 32 best placed woman. Results and closing remarks: it was found that overall average is 18.065 s, with an average interval of 9.333s between hit and resumption of fighting. However, analyzing the periods separately it was found that the hit time is variable and decreases toward the match end.
Keywords: Fencing; Women's Épée; World Fencing 2013; Épée Match.

\section{INTRODUÇÃO}

A esgrima é um "esporte caracterizado por seu praticante ter o objetivo de acertar o adversário com sua arma, sem ser acertado ou, ao menos, receber o menor número toques da arma do oponente possível". Esta modalidade esteve presente em todas as olimpíadas da era moderna. ${ }^{2}$ A esgrima pode ser praticada, tanto por homens, quanto por mulheres- cada qual em sua própria categoria- e possui três modalidades: sabre, florete e espada. O Brasil possui equipes e campeonatos nacionais em todas estas categorias, tanto masculinos como femininos.

Os Campeonatos Mundiais de Esgrima 2013 ocorreram em Budapeste, Hungria, entre 5 e 12 de agosto de 2013. ${ }^{3}$ No entanto, este trabalho levou em consideração o Campeonato Mundial Individual de Espada Feminina, o qual reuniu as melhores espadistas do mundo.

A Espada é uma das modalidades da esgrima, sendo a mais popular de nosso país, possuindo 171 esgrimistas (56 na espada feminina e 115, na masculina) inscritos na Confederação Brasileira de Esgrima. ${ }^{4}$ Além disso, dá nome à arma utilizada pelos seus atletas, os quais são chamados de espadistas.

Em todas as modalidades, um combate competitivo de esgrima possui três aspectos básicos a serem trabalhados e analisados pelos esgrimistas e seus respectivos treinadores: aspectos técnico, físico e tático. ${ }^{5}$ Tanto o aspecto físico, quanto o técnico são recursos a serem utilizados no planejamento tático de cada esgrimis- 
ta, que tem o tempo de combate, como fator de decisão. Segundo Evangelista, ${ }^{6}$ a espada é uma modalidade, em que há uma grande influência da força e da tática. Os toques costumam ser mais demorados e elaborados, havendo uma maior importância para as preparações. ${ }^{1}$

“A supressão de toda convenção e o aumento da superfície válida, aumentam na espada, as chances de tocar e diminuem o valor defensivo da parada".7 O termo "convenção" diz respeito ao florete e ao sabre, onde a mesma determina de quem é o toque, não podendo o esgrimista simplesmente tocar, mas seguir regras mais complexas do que as da espada.

Um scout de um esgrimista é feito com, dentre outros parâmetros, o tempo de preparação para cada toque, pois influencia os aspectos táticos ${ }^{7}$ e "a capacidade tática é extremamente importante e, em alguns casos, decisiva". ${ }^{1}$

Há várias maneiras de se observar matches. Elas podem ser de uma forma geral, individualizadas. Numa forma geral, observam-se, principalmente, os toques válidos executados por todos os atiradores participantes de uma poule ou em um quadro de eliminação. ${ }^{7}$

Além disso, sendo a esgrima um esporte com características próprias, um treinamento físico deve se basear no tempo de execução contínua de esforço e seus intervalos, dentro da especificidade de cada esporte. Czajkowski ${ }^{1}$ diz que no treinamento da esgrima deve-se desenvolver a resistência às fadigas física, emocional, perceptiva e cognitiva.

O desenvolvimento de um plano teórico para a evolução dos aspectos físicos, solicitados aos atletas de Esgrima, especificamente, envolve a capacidade de conseguir transmitir, de forma clara e objetiva, os pressupostos teóricos já existentes sobre a ciência do treinamento desportivo, adaptadas para Esgrima, a cada um dos profissionais responsáveis pela preparação física dos Esgrimistas. ${ }^{8}$

O toque, como já foi citado neste trabalho, é o principal meio para se chegar a 1 (um) ponto na esgrima. Segundo Evangelista, ${ }^{6}$ o toque, na espada, significa atingir, com a ponta da arma, o adversário em qualquer parte de seu corpo e, conforme $\mathrm{FIE}^{9}$ realizando uma pressão mínima de $750 \mathrm{~g}$. Os outros dois meios de se chegar ao ponto são: a saída do adversário pelo limite posterior da pista, ou seja, por retrair além do limite e o cartão vermelho, que dá um ponto ao adversário de quem o recebe. ${ }^{9} \mathrm{Um}$ toque pode ser anulado, quando ocorrer alguma irregularidade.

O objetivo na esgrima é conseguir mais pontos, do que seu adversário. É computado um ponto por toque, o qual pode ocorrer isoladamente ou simultaneamente com o do adversário, constituindo um "toque duplo", que vale um ponto para cada um (FIE, 2013, p.34). Para tal, a arbitragem vale-se de aparelho específico, que acusa cada toque com o acendimento de uma luz-verde para um e vermelha para o outro esgrimista- que bloqueia a segunda se o outro toque não ocorrer em $0,15 \mathrm{~s} .^{9}$

O combate competitivo entre dois esgrimistas é chamado de match. ${ }^{9} \mathrm{O}$ match de espada, em uma competição adulta da FIE, pode ser de dois tipos, diferenciando-se na poule e na fase eliminatória. A poule é um grupo, dentro de uma competição de esgrima, em que todos os esgrimistas se enfrentam. ${ }^{5} \mathrm{O}$ match, em uma poule, dura três minutos ou até um esgrimista atingir cinco pontos. ${ }^{9}$

$\mathrm{Na}$ fase eliminatória, o assalto é composto por três períodos de três minutos cada, com um minuto de intervalo entre estes, ou até um dos esgrimistas atingir quinze pontos, o que acontecer antes. ${ }^{9} \mathrm{O}$ espadista combate até haver um toque ou uma interrupção por parte do árbitro, ocorrendo, assim, esforços intervalados.

Os comandos do árbitro, quando em competição internacional, são na língua francesa. Para iniciar ou reiniciar um combate se dá o comando de "allez" e, para interrompê-lo, o comando de "halt". Se os esgrimistas, em um match não apresentarem disposição para combater, evitando ações decisivas e objetivas, tem-se uma situação de não-combatividade. Isto se dá quando se passa aproximadamente 1 minuto sem ocorrer nenhum toque ou se ambos ficarem a uma distância excessivamente grande, por 15 segundos ou mais. Neste caso, o árbitro deve interromper o combate e passar para o próximo período ou, se no $3^{\circ}$ período, passar para o minuto final. ${ }^{9}$

A ocorrência da não-combatividade pode deixar o combate mais curto para os mesmos 15 pontos, alterando, assim, a parte tática do match. Frente a isso, o presente trabalho visa, perante a escassez de estudos sobre o tema na literatura brasileira, obter dados atualizados que possam orientar a preparação física e tática para um combate de espada feminina.

\section{MÉTODO}

O presente estudo é de natureza aplicada. Valeu-se, para coleta dos dados, do Campeonato Mundial de Esgrima de 2013, realizado em Budapeste, Hungria. Foi realizada uma análise estatística que, em sua execução, teve por método a confecção de scouts, por vídeos oficiais da FIE, de assaltos deste torneio.

Tais scouts levantaram o tempo em que houve combate contínuo e um consequente trabalho de membros inferiores, concluindo em um toque (ponto). As fontes para a revisão bibliográfica foram selecionadas seguindo um controle baseado no reconhecimento no âmbito do esporte e acadêmico e em artigos veiculados em periódicos indexados pela Coordenação de Aperfeiçoamento de Pessoal de Nível Superior (CAPES).

Para a execução da pesquisa, foram considerados os combates eliminatórios entre as 32 melhores colocadas do Campeonato Mundial de Espada Feminina 2013.

A população refere-se a todos os últimos $31 \mathrm{ma}$ tches eliminatórios- da fase de 16 avos de final até a final- da citada competição. Não houve disputa de $3^{\circ}$ lugar. Os matches foram analisados através da cronometragem do tempo entre o comando de "allez" pelo árbitro, até a consecução de 1(um) toque.

Em relação aos toques, foi considerado, como critério de inclusão, o toque ter sido considerado válido pela arbitragem. Toques duplos, por serem simultâneos, foram considerados como 1 (um) toque. O tempo de jo- 
go entre o comando de "allez" e interrupções feitas pela arbitragem, toques inválidos ou outras situações que não resultaram em toque válido, não foi computado.

Visando a apresentação do esporte, foi utilizada literatura especializada a fim de enunciar conceitos e terminologia da Esgrima, principalmente o Regulamento Técnico atualizado da FIE.

Os dados, objeto do presente trabalho, foram coIhidos através de ficha de coleta de dados. Utilizaramse scouts de todos os 31 combates, entre 16 avos de final e a final da modalidade Espada Feminina Individual, do Campeonato Mundial de Esgrima de 2013, sendo os mesmos confeccionados através dos vídeos oficiais da FIE no site http://www.youtube.com/user/FIEvideo.

Os vídeos foram baixados e analisados pelo programa editor de vídeo KINOVEA-0.8.15.

\section{RESULTADOS}

Após análise de todos os matches propostos, verificou-se que, para a consecução de um toque, a média geral foi de 18,065 segundos (s) de esforço contínuo em um combate. A média de tempo entre a realização de um toque e a retomada do combate foi de 9,833s. Este último valor demonstra que há um significativo intervalo entre os esforços.

No entanto, ocorreram muitas diferenças nas médias de cada match (Tabela 1).

A mediana foi $17,881 \mathrm{~s}$, valor central da amostra. A moda é de 16,184 s.

Houve um desvio padrão populacional de 3,994s. Verificou-se, então, que esta média é variável e que somente um match esteve fora da amplitude central, que englobou $96,774 \%$ dos matches. Esta amplitude vai de 10,077 s a 26,053 s.

O match com média aritmética de 6,36 s foi anormal e ocorreu, basicamente, em 1 minuto, pois, nos 3 períodos normais, houve a aplicação da regra de não- combatividade. As esgrimistas ficaram mais de 1 minuto sem realizar toque nestes períodos, decidindo o combate no minuto final.

Se analisarmos os períodos, separadamente, (Gráfico 1) verificaremos que a média aritmética dos $1^{\circ}$ períodos de todos os matches analisados foi de 27,113 s; dos $2^{\circ}$ períodos de 19,282 s; e dos $3^{\circ}$ períodos de $16,514 \mathrm{~s}$.

Do total de toques (615), 27,97\% ocorreram antes de 10 s. Destes, treze $(7,51 \%)$ ocorreram no $1^{\circ}$ período, sessenta e três $(36,42 \%)$ no $2^{\circ}$ período e oitenta e nove $(51,45 \%)$ no $3^{\circ}$ período. Oito $(4,62 \%)$ ocorreram na prorrogação de 1 minuto, (Gráfico 2).

Os toques mais demorados para serem realizados (acima de 50s) foram 3,25\% do total, ou seja, vinte

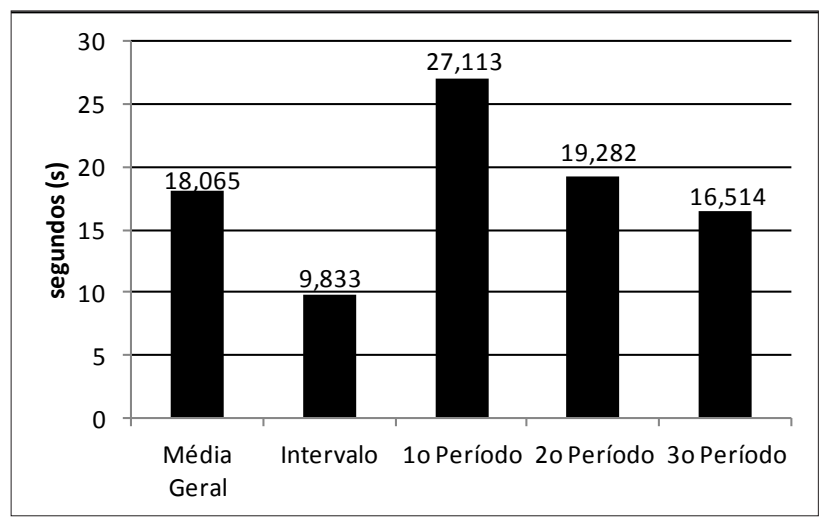

Gráfico 1 - Médias dos matches.

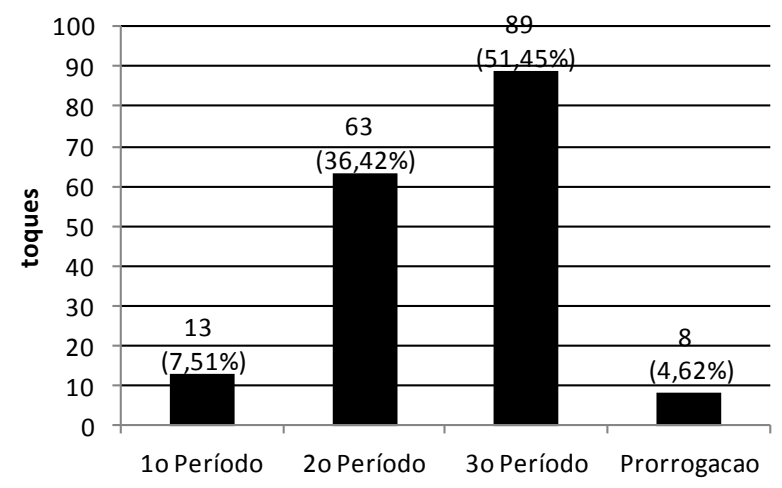

Gráfico 2 - Quantidade de toques abaixo de 10s por período.

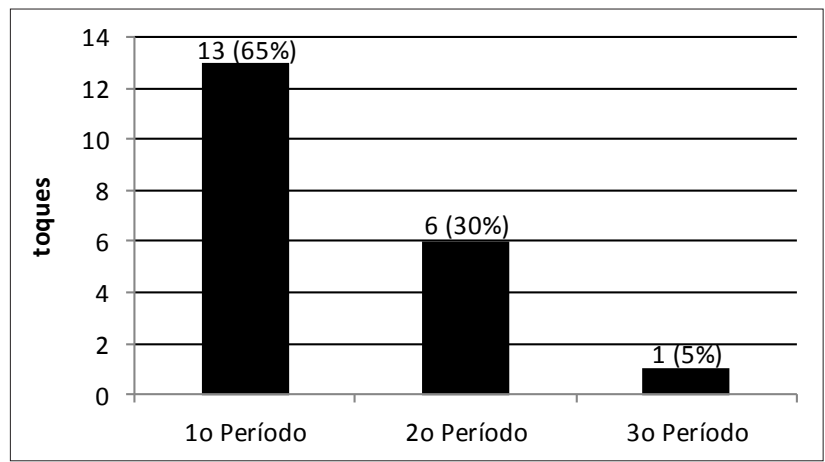

Gráfico 3 - Quantidade de toques acima de 50 s por período.

toques. Como podemos verificar no Gráfico 3, treze destes toques $(65 \%)$ ocorreram no $1^{\circ}$ período, seis (30\%) no $2^{\circ}$ período e um (5\%) no $3^{\circ}$ período.

Foi verificado, também, para fins de complementação à utilização do tempo no combate, que a média aritmética do total cronometrado nos matches foi de 429,723 s. Ou seja, se cada período tem 3 minutos, ou

Tabela 1 - Distribuição das médias de cada match.

\begin{tabular}{ccccc}
\hline Classe & Média & Frequência & Frequência x Média & Frequência relativa \\
\hline $6,360-10,171$ & 6,360 & 1 & 6,360 & 0,032 \\
$10,172-13,983$ & 12,800 & 2 & 25,599 & 0,065 \\
$13,984-17,794$ & 14,649 & 13 & 190,434 & 0,995 \\
$17,795-21,606$ & 19,822 & 9 & 178,394 & 0,567 \\
$21,607-25,417$ & 23,146 & 6 & 138,876 & 0,290 \\
\hline
\end{tabular}

Classe = Tempo médio para a consecucão de um toque em cada match, em segundos.

MIE = Média dos intervalos entre esforços, em segundos. 
180 segundos, pode ser verificado que a média é de dois períodos e mais 69,723 s. Não foi considerado, para fins de cálculo, o minuto de intervalo entre os períodos.

No mesmo sentido, vimos que vinte e oito matches se desenvolveram até o $3^{\circ}$ período, havendo a aplicação da regra de não-combatividade, por 1 minuto sem toque, em quatro destes. Em outros três matches, o combate durou até o $2^{\circ}$ período, quando um dos esgrimistas alcançou 15 (quinze) pontos.

\section{DISCUS5ÃO}

O objetivo do presente estudo foi o levantamento de dados estatísticos referentes à média aritmética do tempo para a consecução de um toque nos 31 últimos matches do Campeonato Mundial de Espada Feminina 2013.

De acordo com Rodrigues, ${ }^{10}$ o tempo de duração de uma frase d'armas -sequência de ações de esgrima com finalidade tática- na Espada é, na média, de 10s. Sendo assim, a mesma autora relata que o exercício ideal para o desenvolvimento aeróbio para um espadista seria um intervalado com séries de 10 s de exercício por 10 s de intervalo. No entanto, em nossa pesquisa, verificamos que a média, no alto nível da Espada Feminina, de exercício contínuo é de 18,065s, com 9,333s de intervalo. Mesmo não havendo, muitas vezes, a execução de frases d'armas durante todo este tempo, há o deslocamento por parte dos esgrimistas.

Além disso, o tempo de preparação para a consecução do toque é variável, podendo chegar a mais de 50s. Sob a análise de tais diferenças, verificou-se que quanto mais próximo do fim da partida, menor é o tempo, ou seja, tem menos preparação. A média do tempo de preparação para o toque dos $3^{\circ}$ períodos é menor do que a média dos $2^{\circ}$ períodos que, por sua vez, é menor do que a média dos $1^{\circ}$ períodos. Tais resultados podem ser analisados sob diversos aspectos como estar atrás no placar e ter pouco tempo para recuperar, fatores psicológicos e emocionais ou ocorrência de fadiga muscular, no caso dos toques mais rápidos.

Chegou-se, ainda, ao resultado de que a maioria dos toques com menos de 10s de preparação ocorreram no $3^{\circ}$ período, enquanto a maioria dos toques com mais de 50s, no $1^{\circ}$ período. Sendo assim, verifica-se que as espadistas buscaram a utilização do tempo para o estudo do adversário ou para cansá-lo, para evitar um adversário mais defensivo ou para evitar uma precipitação, no início do combate. Não foram encontrados outros estudos que realizaram uma análise semelhante ao presente, o que dificulta a discussão dos resultados.

\section{CONSIDERAÇÕES FINAIS}

O presente estudo pôde colher dados relativos à elite mundial da Espada Feminina que, sob os aspectos físicos e táticos, podem contribuir com a melhor formação e/ou o melhor treinamento das espadistas brasileiras. A diminuição do tempo de preparação, com a aproximação do fim do match, bem como os valores relativos às tendências centrais e de dispersão, permitem preparar melhor o treinamento tático em relação ao fator tempo. A constatação da esgrima como exercício intervalado, bem como o estudo das médias de cada período, nos permite orientar a preparação física das espadistas.

\section{REFERÊNCIAS}

1. Czajkowski, Zbigniew. Understanding Fencing: The unity of theory and pratice. Staten Island, NY, USA: SKA Swordplay Books; 2005. 370 p.

2. Ribeiro CJC, Campos DFK. História da Esgrima: da criação à atualidade. Rio de Janeiro: Revista de Educação Física 2007; 137: 65-69.

3. World Fencing Championships. 2013. Disponível em: <http://fencing2013.hu/en/>. Acesso em: 31 maio 2014.

4. Confederação Brasileira de Esgrima (Brasil). Ranking Nacional Absoluto. 2014. Disponível em: <http://www.brasilesgrima. com.br/ranking/2014/ranking2014.htm>. Acesso em: 30 maio 2014.

5. Harmenberg, Johan. Epee 2.0: The Birth of The New Fencing Paradigm. Staten Island, NY, USA: SKA Swordplay Books; 2007. 163 p.

6. Evangelista, Nick. The Art and Science of Fencing. Lincolnwood, Usa: Contemporary Publishing Group, 1996. 288 p.

7. Thirioux, Pierre. Escrime Moderne aus Trois Armes. Paris: Amphora; 1970. 397 p.

8. Pavani, Ricardo. Importância do planejamento de treinamento e das avaliações físicas. Rio de Janeiro: Confederação Brasileira de Esgrima, 2012. Disponível em: <http://www.brasilesgrima. com.br/apostilasecursos/20120821_Avaliacoes_Fisicas _ Ricardo Pavani.pdf $>$. Acesso em: 30 maio 2014.

9. Federacion Internacional de Esgrima (FIE). Regulamento Técnico: Regulamento Técnico de Esgrima. Lausanne, Suica: Fie, 2013. Disponível em: <http://www.fie.ch/download/ rules/es/REGULAMENTO TECNICO.pdf $>$. Acesso em: 15 maio 2014.

10. Rodrigues, Gabriella. Curso Panamericano FIE de Formação de Mestres de Esgrima. Porto Alegre: Confederação Brasileira de Esgrima, 2013. 13 p. Disponível em:<http:// www.brasilesgrima.com.br/apostilasecursos/20131206 GabriellaRodrigues_CursoPanamericanoFIE_Florete2013. pdf >. Acesso em: 05 jun. 2014. 